\title{
Follow-up of skin lesions during the evolution of COVID-19: a case report
}

\author{
Vanessa Lucilia Silveira de Medeiros ${ }^{1}\left[\right.$ (1) Lucas Fagundes Teixeira Silva $^{2}$
}

Received: 18 April 2020 / Revised: 27 April 2020 / Accepted: 30 April 2020 / Published online: 14 May 2020

(c) Springer-Verlag GmbH Germany, part of Springer Nature 2020

\begin{abstract}
The disease caused by the new coronavirus (COVID-19) has many systemic manifestations affecting the upper airways, lungs, gastrointestinal tract and inducing hematological repercussions. With the evolution of the pandemic, skin lesions were observed. However, there is little information about the evolution of the lesions at this moment. The authors report a case of a patient who had more than one exposure to the coronavirus during the evolution of the disease and manifested different types of edematous lesions. The lesions started in the prodromal period and changed their presentation and localization during the evolution of COVID-19. The lesions regressed quickly with the use of corticoid cream and antihistamine. Viral skin lesions are frequent causes of exanthema. However, viral etiology is not always investigated in acute urticarial and atypical erythematous-edematous conditions. The immunological basis of acute urticaria has points in common with COVID-19, justifying the appearance of lesions. Investigation of viral etiology should always be remembered in acute urticarial and edematous conditions.
\end{abstract}

Keywords COVID-19 $\cdot$ Sars-cov-2 $\cdot$ Skin $\cdot$ Urticaria $\cdot$ Virus $\cdot$ Emergent infections

\section{Introduction}

The coronavirus disease (COVID-19) pandemic outbreak started in china with patients who had pneumonia of unknown etiology [1]. Other symptoms presented were dry cough, sore throat, and diarrhea. [1] The etiologic agent was identified as an RNA virus belonging to the Coronaviridae family, being then named as Sars-cov-2.

As the epidemic progressed, other manifestations were observed. Recalcati et al. [3] studied 88 patients admitted in Lecco Hospital, Lombardy, Italy. Of these, 18 patients had skin reactions, and in eight the lesions occurred before hospitalization. These reactions were divided by the authors

Vanessa Lucilia Silveira de Medeiros

vanessalucilia@yahoo.com.br

1 Dermatology Clinic, Tropical Medicine Department of Federal, Clinics Hospital, University of Pernambuco, Av. Prof. Moraes Rego, 1235, Cidade Universitária, Recife 50670-901, PE, Brazil

2 Medical Faculty of Recife, Centro de Ciências Médicas, Federal University of Pernambuco, Av. da Engenharia, 531-611 - Cidade Universitária, Recife 50730-120, PE, Brazil into three forms: erythematous rash, widespread urticaria, and chickenpox-like vesicles [3]. In addition to this study, a case was reported by Joob et al. [4] in Thailand. In this case, the patient presented a rash and a low platelet count and was initially misdiagnosed as dengue. He evolved with respiratory symptoms, being referred to a tertiary hospital and tested positive for sars-cov2 [4].

Despite the existence of skin lesions descriptions, there is little information about their evolutions and pictures about them. Therefore, we report one case that has been following since the prodromal period until the resolution of symptoms.

\section{Case report}

Female patient, 55 years old, intensive care physician, resident of the city of Recife-PE. She has hypothyroidism and overweight comorbidities. The patient had contact with an intensive care unit (ICU) patient previously tested positive for Sars-cov-2 on 03/22/2020. Five days later, few painful erythematous-edematous plaques appeared on the flexor face of forearms and leg extensors (picture 1). Some lesions evolved into bruises. She was treated with betamethasone cream $0.1 \%$ once a day with lesion resolution in 3 days. 
The patient had a second exposure to another ICU patient with COVID-19 on 04/05/2020. On 06/04/20, she had a fever, epistaxis, headache, myalgia, vomiting, and diarrhea. In the skin, she presented pruritic urticarial lesions on the shoulders and inguinal region (Fig. 1). On the palms of his hands, there was erythema and intense itching (Fig. 2).

She was medicated with Bilastine $20 \mathrm{mg}$ one tablet a day for 15 days. Within $48 \mathrm{~h}$, there were no more wheals and erythematous-edematous plaques appeared without itching in the antecubital and popliteal fossae (Fig. 3). The lesions regressed after the use of betamethasone ointment $0.1 \%$ cream once a day for 2 days. On 12/04/2020, the patient presented anosmia, nasal obstruction, asthenia, and mild dyspnea. However, no return of skin lesions. The laboratory showed a positive polymerase chain reaction for ISars-cov-2 and results within normality; lactate dehydrogenase: $321 \mathrm{u} / \mathrm{l}$, C-reactive protein (CPR): $0.7 \mathrm{mg} / \mathrm{L}$, fibrinogen: $304 \mathrm{mg} / \mathrm{dL}$, International Normalized Ratio: 1.00, troponin: $0.03 \mathrm{ng} /$ $\mathrm{mL}$, D-dimer: $400 \mu \mathrm{g} / \mathrm{L}$, total leukocytes: 6890/mm, neutrophils: 4078, eosinophils: 48, lymphocytes: 1897 , platelets: $234.000 / \mathrm{mm}^{3}$, alanine aminotransferase: $42 \mathrm{pg} / \mathrm{mL}$, aspartate aminotransferase: $31 \mathrm{U} / \mathrm{L}$, total bilirubin: $0.5 \mathrm{mg} /$ $\mathrm{dL}$, serum creatinine: $0,73 \mathrm{mg} / \mathrm{dL}$ and. She used only oral zinc and was completely recovered after 10 days of the onset of systemic symptoms.

\section{Discussion}

The pandemic situation caused by COVID-19 is still recent and at the moment there is little information about the cutaneous conditions associated with the virus. The report Joob et al. [4] serves as a warning to health professionals for the possibility of the presence of a rash as the only initial sign of infection with the new Coronavirus.

Viral etiology is not often remembered in the investigation of acute urticaria as it occurs for rash. However, infections by several virus families, such as Parvoviridae and Caliciviridae, in addition to hepatitis A, B, and C viruses [9] are described as causing acute and /or chronic urticaria in children and adults who are not currently using drug therapy. Acute urticaria has an increase in IL-6, PCR, and D-dimer, $[10,11]$ inflammatory
Fig. 1 Erythematous-edematous plaque on the flexor face of the forearm and bruises lesion on the inner thighs
Fig. 2 Exuberant urticarial lesions located on the shoulders. Light erythema and edema on the palms
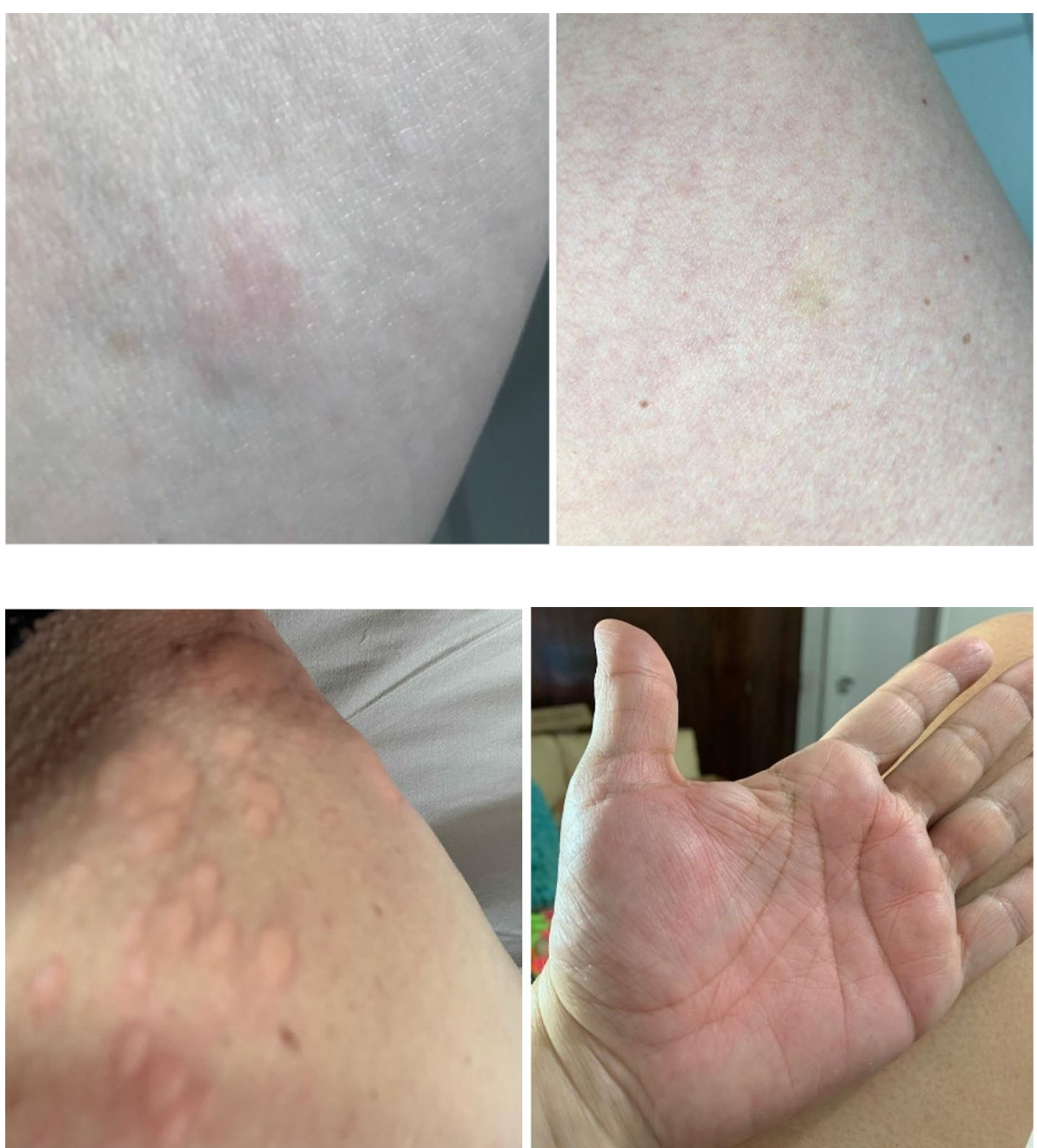
Fig. 3 Erythematous-edematous plaques in the popliteal fossae and antecubital fossa
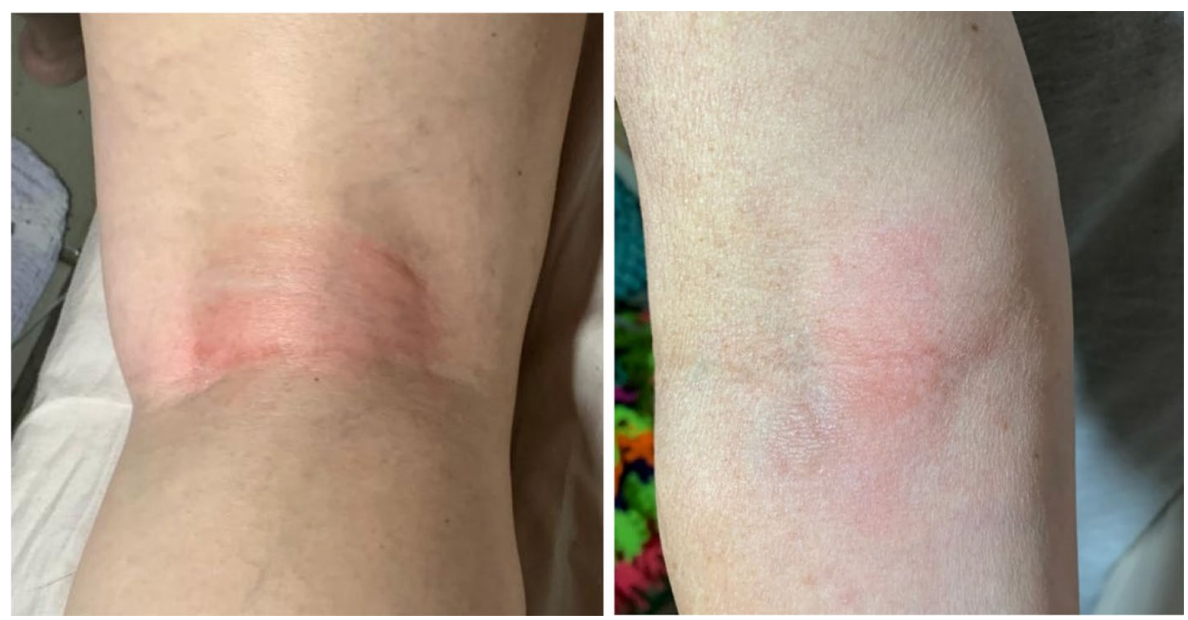

factors that are greatly increased during COVID-19 [12]. The IL-6 is the possible immunological link between them. There are reports of the onset of urticaria in the second infection of dengue [13] and Epstein-Barr reactivation [14]. It is not known if new exposures to the coronavirus increased the immune stimulus, exacerbating the lesions.

It is necessary to use serological tests more frequently to assess viral etiology in patients with acute urticarial or edematous lesions. The initial frustrating lesions, the excellent response to the antihistamine/cortisone cream, and the rapid change to localized lesions practically asymptomatic would prevent the patient from being tested for COVID-19 if she did not have systemic symptoms. Patients with edematous skin lesions or even the classic ones suggestive of viral etiology should be evaluated for COVID-19 and another virosis. Knowing cutaneous manifestations caused by COVID-19 can be an essential step for the early diagnosis of this disease helping to decrease its spread.

Author contributions All authors contributed to the study conception and design. Material preparation, data collection and analysis were performed by VLSM. The first draft of the manuscript was written by LFTS and all authors commented on previous versions of the manuscript. All authors read and approved the final manuscript.

Funding No funding sources.

\section{Compliance with ethical standards}

Conflict of interest No conflict of interest disclosures.

Research involving human participants Not applicable.

\section{References}

1. Wang C, Horby PW, Hayden FG, Gao GF (2020) A novel coronavirus outbreak of global health concern. Lancet 395(10223):470-473

2. Liu SL, Saif L (2020) Emerging viruses without borders: The Wuhan Coronavirus. Viruses. https://doi.org/10.3390/v12020130

3. Imbalzano E, Casciaro M, Quartuccio S, Minciullo PL, Cascio A, Calapai G, Gangemi S (2016) Cutaneous manifestations in COVID-19: a first perspective. J Eur Acad Dermatol. 37(1):18-22

4. Joob B, Wiwanitkit V (2020) COVID-19 can present with a rash and be mistaken for Dengue. J Am Acad Dermatol. https://doi. org/10.1016/j.jaad.2020.03.036

5. Cardoso CW, Paploski IAD, Kikuti M, Rodrigues MS, Silva MMO, Campos GS, Sardi SI, Kitron U, Reis MG, Ribeiro GS (2015) Outbreak of exanthematous illness associated with Zika, Chikungunya, and Dengue viruses, Salvador, Brazil. Emerg Infect Dis 21(12):2274-2276. https://doi.org/10.3201/eid2112.151167

6. Drago F, Ciccarese G, Rebora A, Broccolo F, Parodi A (2016) Pityriasis rosea: a comprehensive classification. Dermatology 232(4):431-437. https://doi.org/10.1159/000445375 (Epub 2016 Apr 21)

7. Abdelmaksoud A (2019) Aciclovir for treatment of pityriasis lichenoides? Clin Exp Dermatol 44(1):64. https://doi.org/10.1111/ ced.13694 (Epub 2018 Jun 20)

8. de Carvalho GC, Hirata FYA, Domingues R, Figueiredo CA, Zaniboni MC, Pereira NV, Sotto MN, Aoki V, da Silva Duarte AJ, Sato MN (2018) Up-regulation of HMGB1 and TLR4 in skin lesions of lichen planus. Arch Dermatol Res 310(6):523-528. https://doi.org/10.1007/s00403-018-1837-5 (Epub 2018 May 4)

9. Imbalzano E, Casciaro M, Quartuccio S, Minciullo PL, Cascio A, Calapai G, Gangemi S (2016) Association between urticaria and virus infections: a systematic review. Allergy Asthma Proc 37(1):18-22. https://doi.org/10.2500/aap.2016.37.3915

10. Kasperska-Zajac A (2012) Acute-phase response in chronic urticaria. J Eur Acad Dermatol Venereol 26(6):665-672

11. Grzanka R, Damasiewicz-Bodzek A, Kasperska-Zajac A (2018) Interplay between acute phase response and coagulation/ 
fibrinolysis in chronic spontaneous urticaria. Allergy Asthma Clin Immunol 14:27. https://doi.org/10.1186/s13223-018-0255-8

12. Zhang W, Zhao Y, Zhang F, Wang Q, Li T, Liu Z, Wang J, Qin Y, Zhang X, Yan X, Zeng X, Zhang S (2020) The use of antiinflammatory drugs in the treatment of people with severe coronavirus disease 2019 (COVID-19): the perspectives of clinical immunologists from China. Clin Immunol 214:108393. https:// doi.org/10.1016/j.clim.2020.108393

13. Chuamanochan M, Chiewchanvit S, Tovanabutra N, Rujiwetpongstorn R, Laosakul K, Maurer M (2019) A case of dengue fever presenting with acute urticaria. Asian Pac J Allergy Immunol. https://doi.org/10.12932/AP-150419-0539
14. Drago F, Merlo G, Cozzani E, Parodi A (2019) Urticaria associated with Epstein-Barr virus reactivation. G Ital Dermatol Venereol 154(6):721-722

Publisher's Note Springer Nature remains neutral with regard to jurisdictional claims in published maps and institutional affiliations. 